\title{
Study on the Different Modes of Action of Potential Trichoderma spp. from Banana Rhizosphere against Fusarium oxysporum f.sp. cubense
}

\author{
Lalngaihawmi $^{1 *}$ and Ashok Bhattacharyya ${ }^{2}$ \\ ${ }^{1}$ Department of Plant Pathology, Assam Agricultural University, Jorhat (785013), \\ Assam, India \\ ${ }^{2}$ Director of Research (Agri.), Assam Agricultural University, Jorhat (785013), Assam, India \\ *Corresponding author
}

\section{A B S T R A C T}

An attempt was made to study the different modes of action of the promising Trichoderma spp. from banana rhizosphere collected from different regions of Assam, Mizoram,

\section{Keywords}

Trichoderma spp., Rhizosphere, Banana, Fusarium oxysporum f.sp. cubense

Article Info

Accepted:

10 December 2018

Available Online:

10 January 2019 Meghalaya and Nagaland. The results from the present investigation revealed that all the potential Trichoderma spp. produced IAA, $\mathrm{NH}_{3}$, siderophore and $\mathrm{HCN}$, though at different levels however, the promising Trichoderma spp. were not able to solubilize phosphate on solid medium containing insoluble inorganic phosphorus source. Considering the possibility of an improved potentiality of combined application, a study was also undertaken to check the effect of combined application of the Trichoderma spp. against Fusarium oxysporum f.sp. cubense (Foc), the causal organism of Fusarium wilt of banana. The per cent inhibition over control was calculated after 48, 72 and 96 hours after inoculation. The result revealed that the efficacy of all the treatments differed significantly with that of control at all the intervals. The per cent inhibition of radial growth of Foc in vitro was observed highest by the combination of the three Trichoderma spp. viz. T. reesei (RMF-25), T. reesei (RMF-13) and T. harzianum (RMF- 28) with 69.18 per cent followed by the combination of $T$. reesei (RMF-25), and $T$. harzianum (RMF-28) with 66.86 per cent and combination of $T$. reesei (RMF-13) and T. harzianum (RMF-28) with 68.60 per cent inhibition of the test pathogen after 96 hours of incubation.

\section{Introduction}

Plant diseases are the result of interactions among the components of disease triangle i.e. host, pathogen and environment. The use of biocontrol agents (BCAs) has been proved to be an environmental friendly disease management strategy in recent years (Xue et al., 2015; Deltour et al., 2017; Fu et al., 2017). Biological control of soil borne diseases caused especially by Fusarium oxysporum is well documented (Marois et al., 1981; Sivan and Chet, 1986; Larkin and Fravel, 1998; Thangavelu et al., 2004). Several reports have previously demonstrated the successful use different species of Trichoderma, Pseudomonas, Streptomyces, non pathogenic Fusarium $(\mathrm{npFo})$ of both rhizospheric and endophytic in nature against Fusarium wilt disease under both glass house and field 
conditions (Lemanceau and Alabouvette, 1991; Alabouvette et al., 1993; Larkin and Fravel, 1998; Weller et al., 2002; Sivamani and Gnanamanickam, 1988; Thangavelu et al., 2001; Rajappan et al., 2002; Getha et al., 2005).

Understanding how the bio control agents work can facilitate optimization of control as well as help to screen for more efficient strains of the agent (Junaid, 2013). Understanding the mechanisms of biological control of plant diseases through the interactions between biocontrol agent and pathogen may allow us to manipulate the soil environment to create conditions conducive for successful biocontrol or to improve bio control strategies (Chet, 1987).

The biocontrol activity is exerted either directly through antagonism of soil-borne pathogens or indirectly by eliciting a plantmediated resistance response (Pozo and Azcón-Aguilar, 2007; Jamalizadeh et al., 2011). Thus, envisaging the potential of rhizospheric microorganisms in plant disease management, the present work has been undertaken to isolate Trichoderma spp. from banana rhizosphere and to explore their biocontrol potential against Fusarium oxysporum f.sp. cubense in vitro.

\section{Materials and Methods}

\section{Collection of samples}

Rhizospheric soil samples were collected from healthy banana rhizosphere of different banana cultivars from Assam, Mizoram, Meghalaya and Nagaland. For collection of the soil samples, the area around healthy banana plants were dug upto a depth of about $5-10 \mathrm{~cm}$. The soils were collected close to the root of the banana plant and kept in polyethylene bags until it was brought to the lab for isolation.

\section{Isolation of Trichoderma spp.}

Microbial culture media viz. Potato Dextrose Agar (PDA) medium and Trichoderma Specific Medium (TSM) were used for the isolation of Trichoderma spp. The Trichoderma spp. were isolated following the protocol described by (Thangavelu and Gopi, 2015) where one gram of each of the rhizospheric soil collected from different cultivars of banana were transferred to $250 \mathrm{ml}$ conical flasks containing $100 \mathrm{ml}$ of sterile distilled water. The flasks were placed in rotary shaker for $10 \mathrm{~min}$ at $120 \mathrm{rpm}$ to dissolve the soil thoroughly. From this, $1 \mathrm{ml}$ of the supernatant were taken and serially diluted upto $10^{-5}$ dilutions. One $\mathrm{ml}$ of the dilution such as $10^{-3}, 10^{-4}, 10^{-5}$ was poured at the centre of sterilized Petri plates. Onto such plates specific media for the fungus were poured and rotated clockwise and anticlockwise. Finally the plates were incubated at $28^{0} \mathrm{C}$ for 2 days and observed for emerging colonies. The fungal colonies were purified by single spore isolation technique and maintained in PDA slants.

\section{Indole acetic acid (IAA) production}

Assay for indole acetic acid (IAA) production was done following the protocol given by Noori and Saud (2012). Five discs of each of the rhizospheric microbes were transferred into respective universal bottles containing 10 $\mathrm{mL}$ of Potato Dextrose Broth (PDB) and incubated on the incubator shaker for $24 \mathrm{~h}$. After $24 \mathrm{~h}$ of incubation, $1 \mathrm{~mL}$ of fungal inoculum was transferred into $250 \mathrm{~mL}$ conical flask containing $100 \mathrm{~mL}$ of sterile PDB with 5 $\mathrm{mL}$ of $0.2 \%(\mathrm{w} / \mathrm{v})$ L-tryptophan and incubated at $28 \pm 2{ }^{\circ} \mathrm{C}$ for $72 \mathrm{~h}$. Conical flask without rhizospheric microbes served as controls or blanks. A $1.5 \mathrm{~mL}$ of aliquot was sampled and centrifuged at 3,000 rpm for $30 \mathrm{~min}, 1 \mathrm{~mL}$ of the supernatant was then added with two drops of orthophosphoric acid and $4 \mathrm{~mL}$ of 
salkowskis reagent $(50 \mathrm{~mL}, 35 \%$ perchloric acid; $1 \mathrm{~mL} 0.5 \mathrm{M}$ ferric chloride, $\mathrm{FeCl}_{3}$ ). Appearance of red color indicates IAA production. To determine the amount of IAA produced from the isolates, the colour density (absorbance) was measured at $535 \mathrm{~nm}$ using spectrophotometer. The IAA produced was compared to the standard graph and expressed as $\mu \mathrm{g} \mathrm{mL}^{-1}$.

\section{$\mathrm{NH}_{3}$ production}

Bakker and Schipper's (1987) protocol was followed to detect the production of $\mathrm{NH}_{3}$ by the three most effective rhizospheric microbes. Freshly grown rhizospheric microbes were inoculated in culture tubes containing 8-10 ml peptone water broth and incubated at $25-26^{\circ} \mathrm{C}$ for 48 hours. Nesseler's reagent $(1 \mathrm{ml})$ was added in each tube. The development of colour from yellow to brownish orange was a positive test for ammonia (Bakker and Schipper, 1987).

\section{Hydrogen cyanide (HCN) production}

HCN production of the three effective rhizospheric microbes was tested qualitatively following the method of Bakker and Schipper (1987). The rhizospheric microbes were inoculated on petriplates containing Tryptic Soya Agar (TSA) supplemented with $4.4 \mathrm{~g} \mathrm{~L}^{-1}$ of glycine. A Whatman filter paper soaked in alkaline picric acid solution $(2.5 \mathrm{~g}$ of picric acid; $12.5 \mathrm{~g}$ of $\mathrm{Na} 2 \mathrm{CO} 3 ; 1000 \mathrm{ml}$ of distilled water) was placed in the upper lid of each plate. The plates were incubated at $25 \pm 2^{\circ} \mathrm{C}$ for 7 days. A change in colour of the filter paper from yellow to light brown, brown or reddish brown was recorded as indication of $\mathrm{HCN}$ production (Meera and Balabaskar, 2012).

\section{Siderophore production}

Chrome Azurol S (CAS) agar method (Schwyn and Neiland, 1987) with a few modification was used to detect the mobilization of iron by the three effective rhizospheric microbes. The rhizospheric microbes were first cultured on PDA plates after which $5 \mathrm{~mm}$ fungal mats from each isolate were transferred to CAS agar plates and incubated at $25 \pm 2{ }^{\circ} \mathrm{C}$ for seven days. FeCAS indicator gave a medium a blue colour. When the iron ligand complex was formed the release of the free dye was accompanied with a color change. Iron mobilization was done via the production of complex acids or siderophores. The Fe (III) gave the agar a rich blue color and concentration of siderophores excreted by iron starved organisms gave a color change to orange. The orange hallow surrounding the colony indicated the excretion of siderophore and its dimension evaluated the amount of siderophore excreted.

\section{Phosphate solubilizing activity}

The three best performing rhizospheric microbes were screened qualitatively for inorganic phosphate solubilization as per methodology described by Gupta et al., (1994). A 5mm mycelia disc of each isolates were placed on the centre of Pikovskaya agar with insoluble tricalcium phosphate (TCA) and incubated at $25 \pm 2{ }^{\circ} \mathrm{C}$ for 7 days. The experiment was performed on CRD with five replications each. After incubation, the colonies with clear halo zones (solubilizing zone) around colony indicated positive solubilization of mineral phosphate (Noori and Saud, 2012).

\section{In vitro testing of promising Trichoderma spp. for their compatibility}

The Compatibility studies were carried out to observe whether the selected antagonists were compatible with each other against Foc. Dual culture method described by Dennis and Webster (1971) was employed to observe for the zone of inhibition. The test was carried in 
vitro with all possible permutations and combinations to study their compatibility with each other.

Effect of promising Trichoderma spp. against Foc individually and in combination

Efficacy of the promising antagonists was studied individually and in combinations against Foc in vitro based on the compatibility test following Zegeye et al., (2011) with slight modification. The design of the experiment followed was completely randomized design (CRD) with five replications for each treatment (individually or in combination).

\section{Results and Discussion}

\section{Identification of Trichoderma spp.}

All the rhizospheric microbes isolated during the present investigation were tested for their antagonistic activity against Foc by dual culture plate technique. Identification of Trichoderma spp. was carried out only for the three best performing rhizospheric microbes by sequencing of $18 \mathrm{~S}$ rRNA and the results revealed that the first (RMF-25) and the second best (RMF-13) promising rhizospheric microbes were Trichoderma reesei while the third best promising rhizospheric microbe (RMF-28) was $T$. harzianum. These three potential Trichoderma spp. were then used for testing their different modes of action like production of IAA, $\mathrm{NH}_{3}, \mathrm{HCN}$, Siderophore and Phosphate solubilisation activity.

\section{Indole acetic acid (IAA) production}

The results for the production of IAA have been presented in Table 1 and depicted in Plate 2. In the present investigation, it was observed that all Trichoderma spp. elucidated positive results for IAA production. Maximum IAA production was observed in $T$. reesei (RMF-25) with $13.38 \mu \mathrm{g} \mathrm{mL} \mathrm{mL}^{-1}$ of IAA followed by $T$. harzianum (RMF-28) and $T$. reesei (RMF-13) with $9.346 .32 \mu \mathrm{g} \mathrm{mL}^{-1}$ IAA production respectively. IAA has been implicated in virtually every aspect of plant growth and development, as well as defense responses. The result of the present investigation is also supported by the findings of Mohiddin et al., (2017) who isolated Trichoderma species from chilli rhizosphere. Their studies revealed that the amount of IAA produced by Trichoderma spp. ranged from

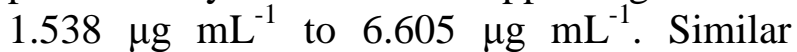
findings were recorded several workers (Badawi et al., 2011; Aarti and Meenu, 2015) who also reported the amount of IAA produced by Trichoderma spp. as in the range obtained in present investigation.

\section{$\mathrm{NH}_{3}$ production}

The results for $\mathrm{NH}_{3}$ production has been presented in Table 1. All the Trichoderma spp. showed positive result for ammonia production by turning initial peptone water broth from yellow to brownish orange (Plate 2 ). It had also been observed that $T$. reese $i$ (RMF-13) produced more amount of $\mathrm{NH}_{3}$ while $T$. reesei (RMF-25) and $T$. harzianum (RMF-28) produced mediocre amount of $\mathrm{NH}_{3}$. Ammonia production by the Trichoderma isolates may influence plant growth indirectly which is directly or indirectly useful for plants (Ahemad and Kibret, 2014). The ACC (1aminocyclopropane-1- carboxylic acid) synthesized in plant tissues by ACC synthase is thought to be exuded from plant roots and be taken up by neighboring micro-organisms. Trichodrema may hydrolyze ACC to ammonia (Ahemad and Kibret, 2014). The result of the present investigation is in agreement with reports of several workers (Aarti and Meenu, 2015; Chadha et al., 2015) who reported the production of ammonia by Trichoderma spp. Similar findings was also reported by Mohiddin et al., (2017) who reported that out of 20 Trichoderma spp., isolated from chilli 
rhizosphere, 13 isolates were found to produce ammonia.

\section{Hydrogen cyanide (HCN) production}

The results of $\mathrm{HCN}$ production (Table 1) revealed that $T$. reesei (RMF-13) and $T$. harzianum (RMF-28) were able to produce $\mathrm{HCN}$ as there was a change in colour of filter paper from yellow to reddish brown (Plate 3). It was also observed that $T$. harzianum (RMF28) produced more amount of $\mathrm{HCN}$ as compared to $T$. reesei (RMF-13) which produced mediocre amount. However, HCN production was not observed in $T$. reesei (RMF-25). HCN production is an important trait found in various soil micro-organisms as it indirectly promotes plant growth by controlling some soil borne diseases (Kremer and Souissi, 2001; Siddiqui et al., 2006). This is mainly due to cyanide production by microbes which can acts as a general metabolic inhibitor to avoid predation or competition without harming the host plants (Noori and Saud, 2012.). The result of the present investigation is also supported by Aarti and Meenu (2015), Ng et al., (2015) and Mohiddin et al., (2017) who reported the positive production of $\mathrm{HCN}$ by Trichoderma spp.

\section{Siderophore production}

The results (Table 1 and Plate 4) revealed that T. reesei (RMF25) and $T$. reesei (RMF-13) were able to secrete siderophore by the production of yellow halo surrounding the growing Trichoderma spp. The observations revealed that $T$. reesei (RMF-25) secretes more amount of $\mathrm{HCN}$ as compared to T. reesei (RMF-13) which produced mediocre amount however secretion of siderophore production was not observed by T. harzianum (RMF 28). Siderophores are low molecular iron chelating compounds produced by fungi and bacteria under iron stress condition (Ghosh et al.,
2017). Siderophores are produced for scavenging iron from the environment and have an high affinity for iron (III) (Hider and Kong, 2010). $\mathrm{Fe}^{3+}$-chelating molecules can be beneficial to plants because they can solubilise the iron which is otherwise unavailable and can suppress the growth of pathogenic microorganisms by depriving the pathogens of this necessary micronutrient (Leong, 1986). However siderophore production can vary considerably depending on the strain of Trichoderma spp (Anke et al., 1991). This is in conformity with the result of the present finding as secretion of siderophore was not observed in T. harzianum (RMF 28). Gosh et al., (2017) and Vinale et al., (2013) also revealed that antagonistic spp. of Trichoderma namely $T$. viride, $T$. harzianum, $T$. longibrachiatum and T. asperellum produced considerable amount of siderophore

\section{Phosphate solubilizing activity}

The result of the qualitative estimation of phosphate solubilisation for all the Trichoderma spp. did not show any clear zone on Pikovskaya's Agar after incubation at room temperature for 0-7 days (Table 1 and Plate 5). The finding of the present investigation was in contrast with El-Katatny (2004), who reported that Trichoderma isolates are relatively good in P-solubilization. Phosphate solubilization of Trichoderma species is one of the mechanisms of these fungi as the plant growth promoting fungi. However, the ability of Trichoderma species depends on the kind and strain of Trichoderma and source of phosphate (Kapri and Tewari, 2010; Promwee, 2011). Our finding was also supported by many workers (Rawat and Tewari, 2011; Promwee et al., 2014; Ng et al., 2015) who reported that even though Trichoderma species revealed good mycelia growth, there was no formation of halo-zone on the solid medium containing insoluble inorganic phosphorus source. In addition, Nautiyal (1999) reported that the 
criterion for isolation of phosphate solubilizers based on the formation of a visible halo-zone on Pikovskaya's agar is not a reliable technique because many isolates of Phosphate Solubilizing Microorganisms (PSM), which did not show any clear zone on agar plates, could be able to solubilize insoluble inorganic phosphates in liquid medium.

In vitro testing of effective rhizospheric microbes for their compatibility

Considering the possibility of an improved potentiality of combined application of the three best performing rhizospheric microbes, a study was undertaken to record the combined effect of the rhizospheric microbes in comparison to single application. The experiment was carried out in all permutations and combination amongst the rhizospheric microbes. The result of the experiment revealed that all the Trichoderma spp. were found to be compatible with each other in all combinations without inhibiting each other (Plate 6). Such reports of positive compatibility amongst the rhizospheric microbes have been reported by many researchers (Dandurand and Knudsen 1993; Duffy et al., 1996; Raupach and Kloepper, 1998). Further, since they are of one fungus their compatibility is justified (Thangavelu and Gopi, 2015a; Baruah et al., 2018).

Effect of promising rhizospheric microbes against Foc individually and in combination

The effect of the three promising Trichoderma spp. were further studied to observe their efficacy in reducing the growth of Foc individually as well as in combinations. The result revealed that the efficacy of all the treatments differed significantly with that of control at all the intervals. The per cent inhibition over control was calculated after 48 , 72 and 96 hours after inoculation. The results for the combined effect of Trichoderma spp. against Foc have been presented in Table 2 and depicted in Plate 7. After 96 hours of incubation, the per cent inhibition of radial growth of Foc in vitro was observed highest by the combination of the three Trichoderma spp. viz. T. reesei (RMF-25), T. reesei (RMF13) and T. harzianum (RMF- 28) with 69.18 per cent followed by the combination of $T$. reesei (RMF-25), and T. harzianum (RMF 28) with 66.86 per cent and combination of $T$. reesei (RMF-13) and T. harzianum (RMF 28) with 68.60 per cent inhibition of the test pathogen.

Table.1 Production of IAA, $\mathrm{NH}_{3}, \mathrm{HCN}$, Siderophore and Phosphate solubilisation activity by isolated Trichoderma spp

\begin{tabular}{|r|c|c|c|c|c|c|}
\hline $\begin{array}{c}\text { Sl. } \\
\text { No. }\end{array}$ & Trichoderma spp. & $\begin{array}{c}\text { IAA } \\
\text { Production } \\
\left(\boldsymbol{\mu g} \mathbf{~ m L}^{-\mathbf{1}}\right)\end{array}$ & $\begin{array}{c}\text { NH3 } \\
\text { Production }\end{array}$ & $\begin{array}{c}\text { HCN } \\
\text { Production }\end{array}$ & $\begin{array}{c}\text { Siderophore } \\
\text { Production }\end{array}$ & $\begin{array}{c}\text { Phosphate } \\
\text { Solubilization }\end{array}$ \\
\hline 1. & T. reesei (RMF-25) & 13.38 & + & - & ++ & - \\
\hline 2. & T. reesei (RMF-13) & 6.32 & ++ & + & + & - \\
\hline 3. & $\begin{array}{r}\text { T. harzianum } \\
\text { (RMF-28) }\end{array}$ & 9.34 & + & ++ & - & - \\
\hline+ & $\begin{array}{l}\text { indicates mediocre amount of production } \\
\text { indicates more amount of production } \\
\text { indicates no production }\end{array}$ \\
\hline-
\end{tabular}


Table.2 Effect of Trichoderma spp. individually and in combination on the growth and per cent inhibition of Foc

\begin{tabular}{|c|c|c|c|c|c|c|c|}
\hline \multirow[t]{2}{*}{$\begin{array}{l}\text { Sl. } \\
\text { No. }\end{array}$} & \multirow[t]{2}{*}{ Combinations } & $\begin{array}{l}\text { Growth } \\
\text { of Foc } \\
\text { (cm) }\end{array}$ & $\begin{array}{l}\text { Per cent } \\
\text { inhibition } \\
\text { of Foc }\end{array}$ & $\begin{array}{l}\text { Growth } \\
\text { of Foc } \\
\text { (cm) }\end{array}$ & $\begin{array}{l}\text { Per cent } \\
\text { inhibition } \\
\text { of Foc }\end{array}$ & $\begin{array}{l}\text { Growth } \\
\text { of Foc } \\
\text { (cm) }\end{array}$ & $\begin{array}{l}\text { Per cent } \\
\text { inhibition } \\
\text { of Foc }\end{array}$ \\
\hline & & \multicolumn{2}{|c|}{48 hrs } & \multicolumn{2}{|c|}{$72 \mathrm{hrs}$} & \multicolumn{2}{|c|}{ 96hrs } \\
\hline 1. & T. reesei (RMF25) & 1.12 & 46.66 & 1.14 & 55.81 & 1.16 & 66.27 \\
\hline 2. & T. reesei (RMF13) & 1.14 & 45.71 & 1.18 & 54.26 & 1.2 & 65.12 \\
\hline 3. & T. harzianum (RMF 28) & 1.16 & 44.76 & 1.16 & 55.03 & 1.18 & 65.69 \\
\hline 4. & $\begin{array}{l}\text { T. reesei }(\mathrm{RMF} 25)+T . \\
\text { reesei }(\mathrm{RMF} 13)\end{array}$ & 1.06 & 49.52 & 1.08 & 58.13 & 1.10 & 68.02 \\
\hline 5. & $\begin{array}{l}\text { T. reesei }(\mathrm{RMF} 25)+T \\
\text { harzianum }(\mathrm{RMF} 28)\end{array}$ & 1.1 & 47.62 & 1.12 & 56.58 & 1.14 & 66.86 \\
\hline 6. & $\begin{array}{l}\text { T. reesei }(\mathrm{RMF}-13)+T . \\
\text { harzianum }(\mathrm{RMF} 28)\end{array}$ & 1.04 & 50.47 & 1.06 & 58.91 & 1.08 & 68.60 \\
\hline 7. & $\begin{array}{l}T . \text { reesei }(\mathrm{RMF} 25)+T \\
\text { reesei }(\mathrm{RMF} 13)+T . \\
\text { harzianum }(\mathrm{RMF} 28)\end{array}$ & 1.02 & 51.42 & 1.04 & 59.68 & 1.06 & 69.18 \\
\hline 8. & Control & 2.1 & 0.00 & 2.58 & 0.00 & 3.44 & 0.00 \\
\hline & $S E d \pm$ & 0.06 & & 0.04 & & 0.03 & \\
\hline & $C D(p=0.05)$ & 0.12 & & 0.09 & & 0.07 & \\
\hline
\end{tabular}

Plate.1 Indole Acetic Acid (IAA) production test by promising Trichoderma spp.
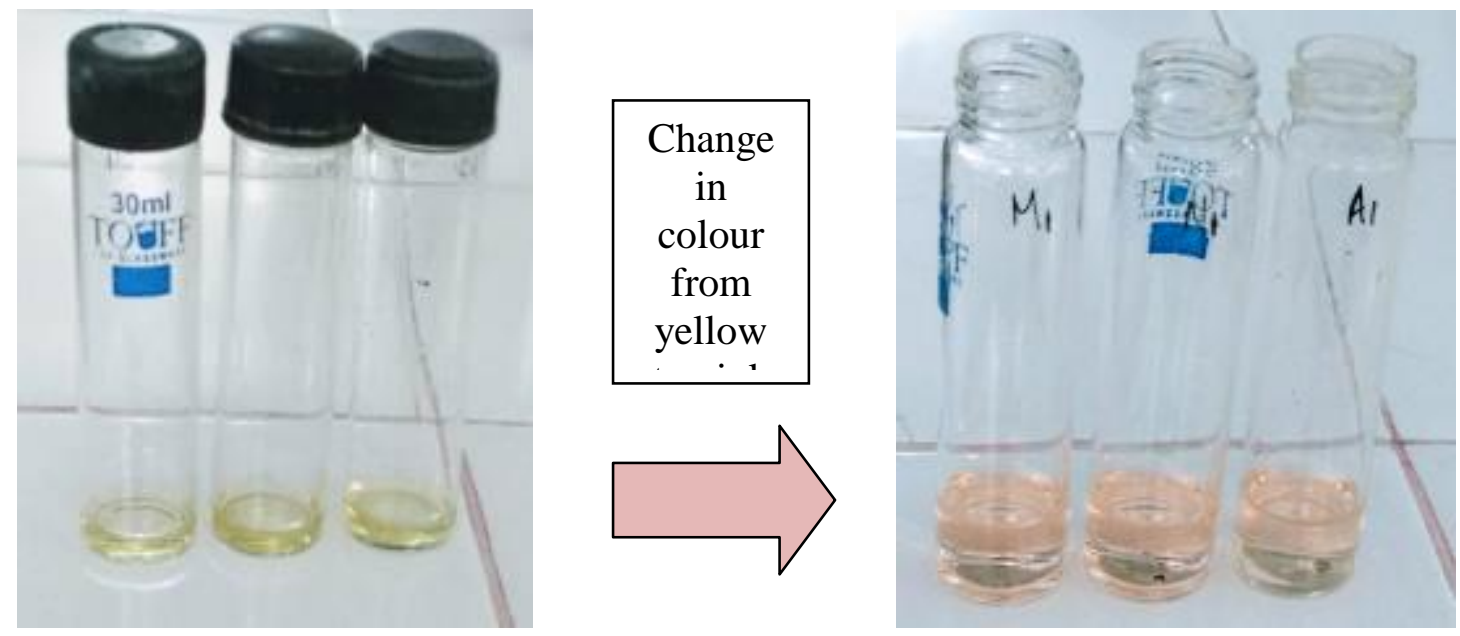
Plate. $2 \mathrm{NH}_{3}$ production test by promising Trichoderma spp.
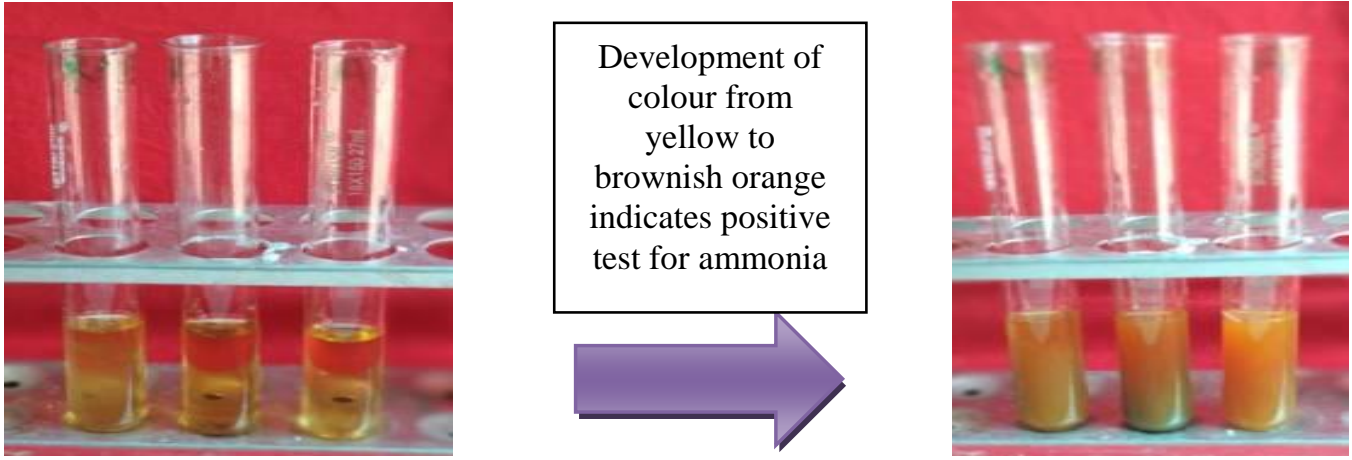

Plate. 3 HCN production test by promising Trichoderma spp.

A) T. reesei (RMF-25), B) T. reesei (RMF-13), C) T. harzianum (RMF-28)

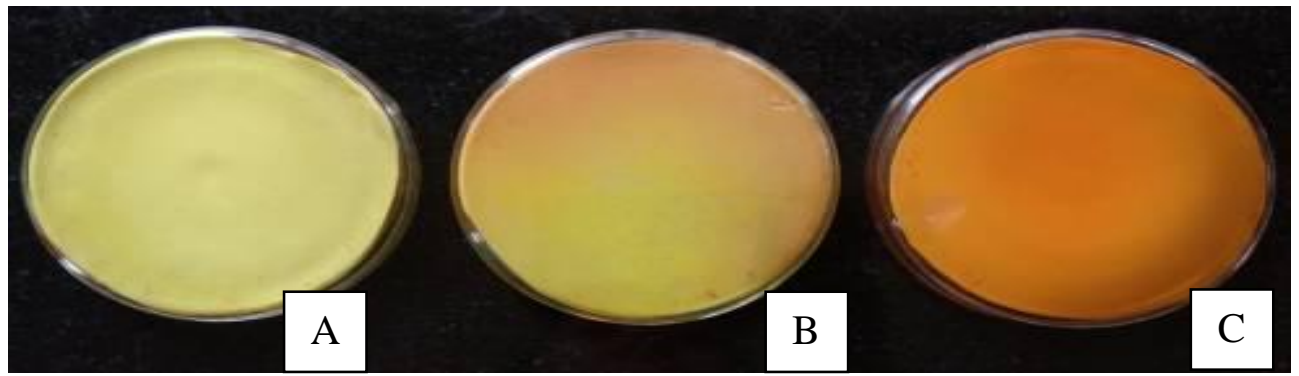

Plate.4 Siderophore production test by promising Trichoderma spp.

A) T. reesei (RMF-25), B) T. reesei (RMF-13), C) T. harzianum (RMF-28)

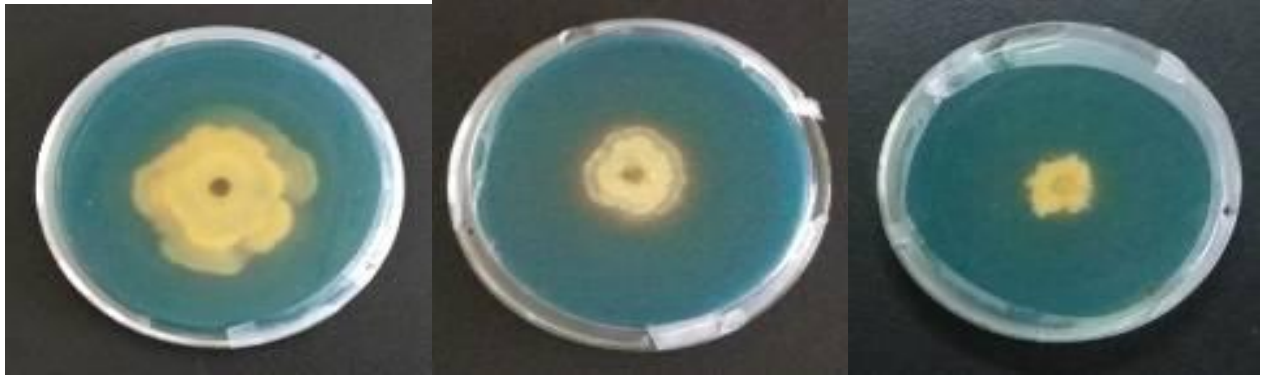

A)

B)

C)

Plate.5 Phosphate solubilisation test by promising Trichoderma spp.

A) T. reesei (RMF-25), B) T. reesei (RMF-13), C) T. harzianum (RMF-28)

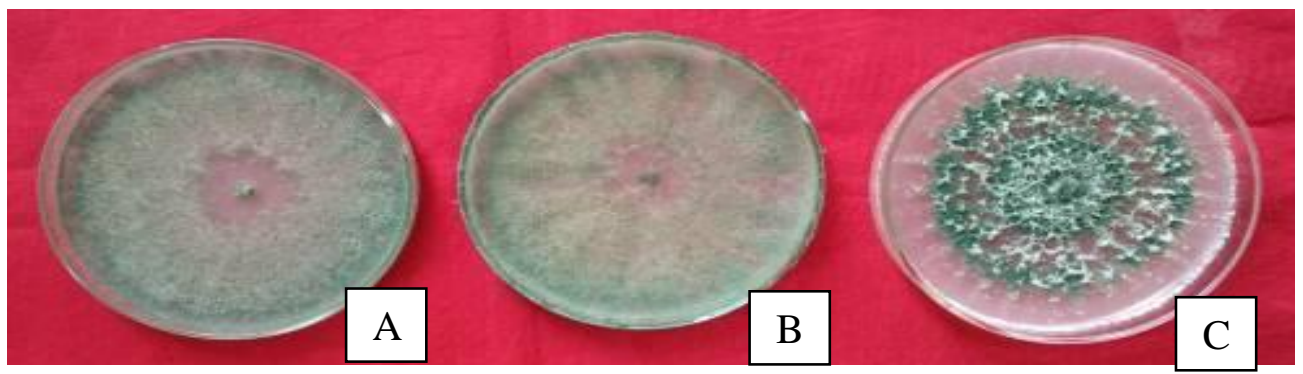

I) Front view 
Plate.6 In vitro testing of promising Trichoderma spp. for their compatibility A) T. harzianum $(\mathrm{RMF}-28)+T$. reesei $(\mathrm{RMF}-13)+T$. reesei $(\mathrm{RMF}-25) \mathrm{B})$ T. reesei $(\mathrm{RMF} 25)+$ T. reesei $(\mathrm{RMF} 13) \mathrm{C}:$ T. reesei $(\mathrm{RMF} 13)+T$. harzianum $(\mathrm{RMF} 28) \mathrm{D}: T$. reesei $(\mathrm{RMF} 25)+T$. harzianum (RMF 28)

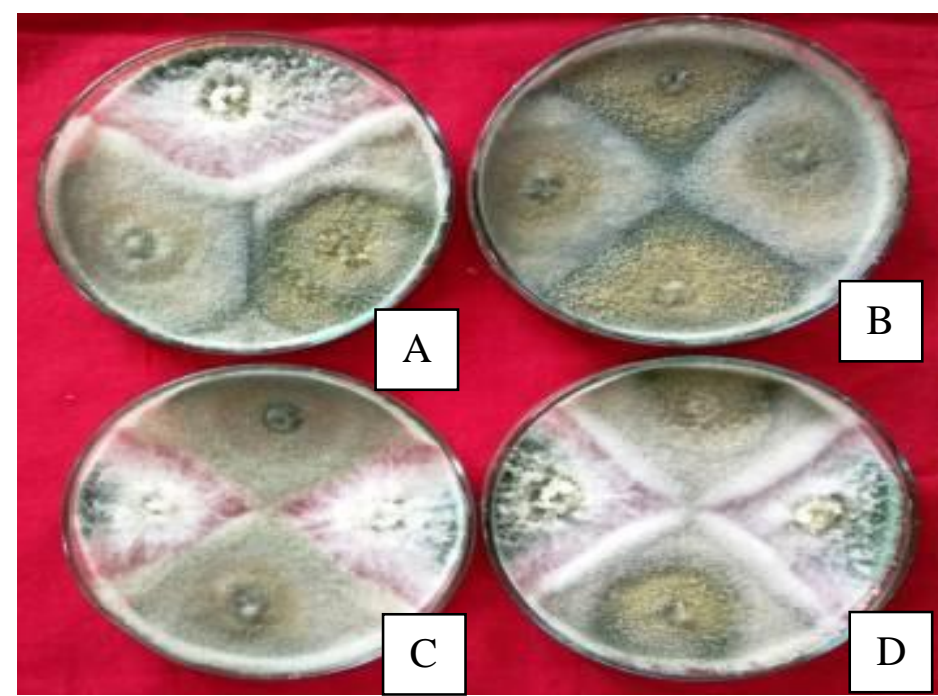

Plate.7 Effect of promising Trichoderma spp. individually and in combination against Foc A) Control B) T. reesei (RMF-25) alone C) T. reesei (RMF-13) alone D) T. harzianum (RMF-28) alone E) T. reesei $(\mathrm{RMF}-25)+T$. reesei $(\mathrm{RMF}-13) \mathrm{F}) T$. reesei $(\mathrm{RMF}-25)+T$. harzianum (RMF-28), G) T. reesei $(\mathrm{RMF}-13)+$ T. harzianum $(\mathrm{RMF}-28) \mathrm{H}) T$. reesei $(\mathrm{RMF}-$ $25)+T$. harzianum $(\mathrm{RMF}-28)+T$. reesei $(\mathrm{RMF}-13)$

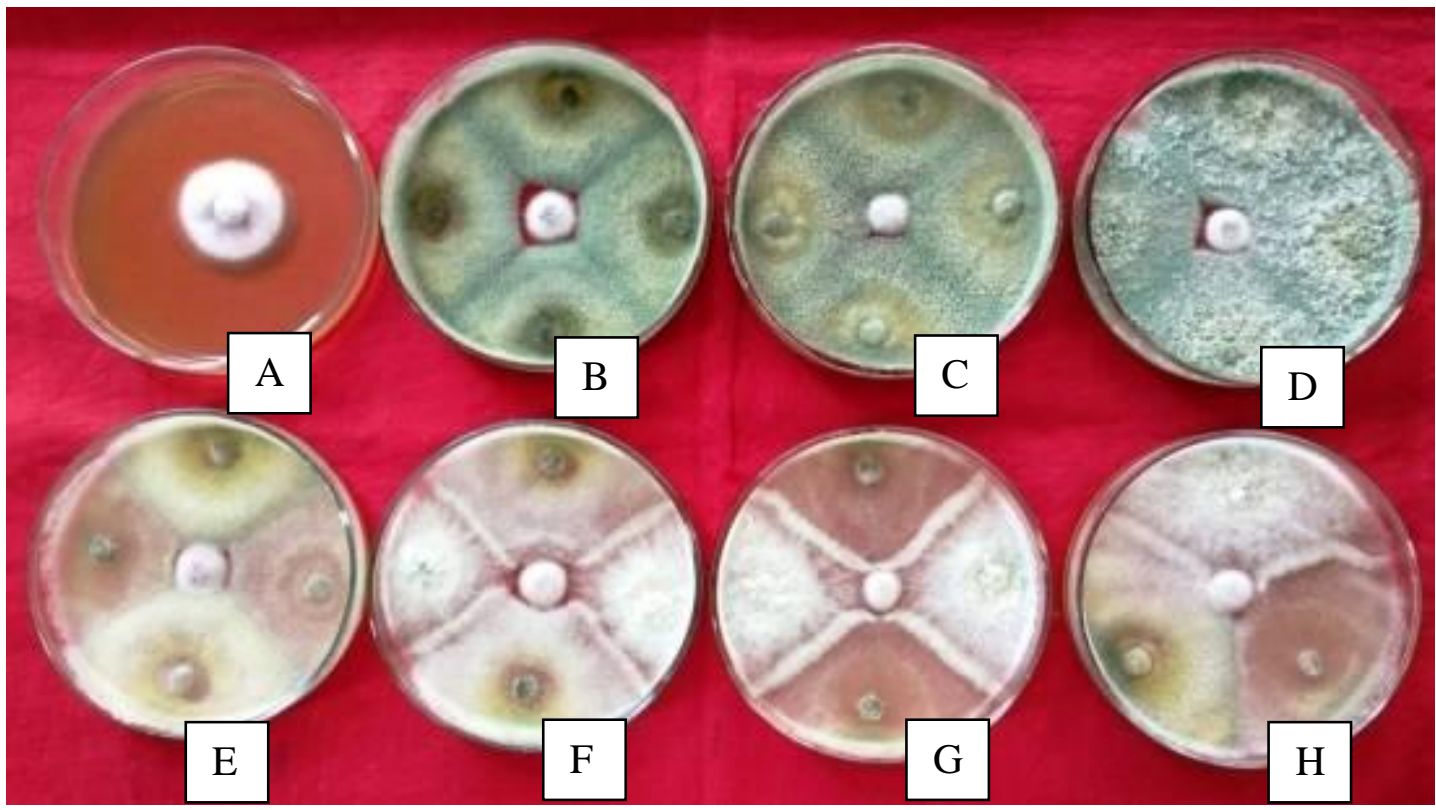

The percent inhibition recorded by the rest of the rhizospheric microbes either singly or in combination ranged from 65.12 per cent in case of $T$. reesei (RMF-13) alone to 68.02 per cent in case of combination of $T$. reesei (RMF-25) and T. reesei (RMF13). 
It had been reported that combined application of biocontrol agents is more effective over a single biocontrol agent in the management of several plant diseases (Crump, 1998; Pierson and Weller, 1994). Similar finding was reported by Akrami et al., (2011) who reported that $T$. harzianum and $T$. asperellum isolates and their combination reduced Fusarium rot disease severity from 20 to 44 per cent and increased the dry weight from 23 to 52 per cent in lentil under glasshouse conditions. Thangavelu and Gopi (2015a) reported that the rhizospheric and endophytic Trichoderma isolates, which recorded effective control against Foc pathogen were compatible with each other under in vitro condition. Otadoh Sobre et al., (2011) also evaluated Isolates of Trichoderma from Embu soils for their ability to control Fusarium oxysporum f. sp. phaseoli., in vitro They found that Trichoderma solates significantly reduced the mycelial growth of the pathogen where combination of $T$. reesel and T. koningii were most effective. Since the data obtained from the present investigation also indicates significant reduction in the growth of Foc, thus it corroborates with the findings of the earlier workers.

\section{References}

Aarti, T., and Meenu, S. 2015. Role of volatile metabolites from Trichoderma citrinoviride in biocontrol of phytopathogens. Int. J Res Chem Environ. 5: 86-95.

Ahemad, M., and Kibret, M. 2014. Mechanisms and Applications of Plant Growth Promoting Rhizobacteria: Current Perspective. Journal of King Saud University-Science. 26: 1-20.

Akrami, M., Golzary, H., and Ahmadzadeh, M. 2011. Evaluation of different combinations of Trichoderma species for controlling Fusarium rot of lentil. African. J. Biotechnol. 10: 2653-2658.
Alabouvette, C., Lemanceau, P., and Steinberg, C. 1993. Recent advances in the biological control of Fusarium wilts. Pesticides Science. 37: 365-373.

Anke, H., KinnKarl-Erik, J., and Sterner, B. O. 1991. Production of siderophores by strains of the genus Trichoderma. Biol. Metals. 4:176-180.

Bakker, A.W., and Schippers, B. 1987. Microbial cyanide production in the rhizosphere in relation to potato yield reduction and Pseudomonas spp.mediated plant growth-stimulation. Soil Biology and Biochemistry. 19: 451-457.

Baruah, N., Bhattacharyya, A., Thangavelu, R., and Puzari, K. C. 2018. In vitro Screening of Native Banana Rhizospheric Microbes and Endophytes of Assam against Fusarium oxysporum f. sp. cubense. Int. J. Curr. Microbiol. App. Sci. 7(6):1575-1583.

Chadha, N., Prasad, R., and Varma, A. 2015. Plant promoting activities of fungal endophytes associated with tomato roots from central Himalya, India and their interaction with Piriformospora indica. International Journal of Pharma and Bio Sciences. 6: 333-343.

Chet, I. 1987. Trichoderrna - application, mode of action, and potential as a biocontrol agent of soilborne plant pathogens. In Innovative Approaches to Plant Disease Control. Pp. 137-160. Edited by I. Chet. New York: John Wiley.

Dandurand, L. M. and Knudsen. 1993. Influence of Pseudomonas fluorescence on hyphal growth and biocontrol activity of Trichoderma harzianum in the spermosphere and rhizosphere of pea. Phytopathol. 83: 265-270.

Deltour, P., França, S. C., Pereira, O. L., Cardoso, I., Höfte, M. 2017. Disease suppressiveness to Fusarium wilt of banana in an agroforestry system: Influence of soil characteristics and 
plant community. Agric Ecosyst Environ. 239: 173-181.

Dennis, C., and Webster, J. 1971. Antagonistic properties of species groups of Trichoderma. II. Production of volatile antibiotics. Transact. Brit. Mycol. Soc. 57: 41-48.

Duffy, B. K., Simon, A., and Weller, D. M. 1996. Combinations of Trichoderma koningii and fluorescent pseudomonad for control of take-all of wheat. Phytopathol. 86: 188-194.

El-Katatny, M. S. 2004. Inorganic phosphate solubilisation by free or immobilized Trichoderma harzianum cells in comparison with some other soil fungi. Egyptian J. Biotechnol. 17: 1338-1353.

Fu, L., Penton, C. Y., Ruan, Y. Z., Shen, Z. Z., and Shen, Q. R. 2017. Inducing the rhizosphere microbiome by biofertilizer application to suppress banana Fusarium wilt disease. Soil Biol Biochem. 104: 39-48.

Getha, K., Vikineswary, S., Wong, W., Seki, T., Ward, A. and Goodfellow, M. 2005. Evaluation of Streptomyces sp. strain G10 for suppression of Fusarium wilt and rhizosphere colonization in pot grown banana plantlets. Journal of Industrial Microbiology and Biotechnology. 32: 24-32.

Ghosh, S. K., Banerjee, S., and Sengupta, C. 2017. Bioassay, characterization and estimation of siderophores from some important antagonistic fungi. JBiopest. 10(2): 105-112.

Gupta, R. R., Singal, R., Shanker, A., Kuhad, R. C., Saxena, R. K. 1994. A modified plate assay for screening phosphate solubilizing microorganisms. J. Gen. Appl. Microbiol. 40: 255-260.

Jamalizadeh, M., Etebarian, H. R., Aminian, H., and Alizadeh, A. 2011. A review of mechanisms of action of biological control organisms against post-harvest fruit spoilage. EPPO Bulletin. https://doi.org/10.1111

/j.1365-

2338.2011.02438.x

Junaid, J. M., Dar, N. A., Bhat, T. A., Bhat, A. H., and Bhat, M. A. 2013. Commercial Biocontrol Agents and Their Mechanism of Action in the Management of Plant Pathogens. International Journal of Modern Plant \& Animal Sciences. 1(2): 39-57.

Kapri, A., and Tewari, L. 2010. Phosphate solubilization potential and phosphatase activity of rhizospheric Trichoderma spp. Brazilian Journal of Microbiology. 41(3): 787-795.

Kremer, R. J., and Souissi, T. 2001 Cyanide production by rhizobacteria and potential for suppression of weed seedling growth. Current Microbiol. 43: 182-186.

Larkin, R. and Fravel, D. 1998. Efficacy of various fungal and bacterial biocontrol organisms for the control of Fusarium wilt of tomato. Plant Disease. 82: 10221028.

Larkin, R. and Fravel, D. 1998. Efficacy of various fungal and bacterial biocontrol organisms for the control of Fusarium wilt of tomato. Plant Disease. 82: 10221028.

Lemanceau, P., and Alabouvette, C. 1991. Biological control of Fusarium diseases by fluorescent Pseudomonas and nonpathogenic Fusarium. Crop Protection. 10: 279-286.

Marois, J. J., Mitchel, D. J., and Somada, R. M. 1981. Biological control of Fusarium crown and root rot of tomato under field condition. Phytopathology. 12: 1257-1260.

Meera, T., and Balabaskar, P. 2012. Isolation and characterization of Pseudomonas fluorescens from rice fields. International Journal of Food, Agriculture and Veterinary Sciences. 2 (1):113-120.

Mohiddin, F. A., Bashir, I., Padder, S. A., and 
Hamid, B. 2017. Evaluation of different substrates for mass multiplication of Trichoderma species. Journal of Pharmacognosy and Phytochemistry. 6(6): 563-569.

Nautiyal, C. S. 1999. An efficient microbiological growth medium for screening phosphate solubilising microorganisms. FEMS Microbiology Letters, 170: 265-270. http://dx.doi.org/ 10.1111/j.1574-6968.1999.tb13383.x

Ng, L. C., Ngadin, A., Azhari, M., and Zahari, N. A. 2015. Potential of Trichoderma spp. as Biological Control Agents Against Bakanae Pathogen (Fusarium fujikuroi) in Rice. Asian Journal of Plant Pathology. 9: 46-58.

Noori, M. S. S., and Saud, H. M. 2012. Potential plant growth-promoting activity of Pseudomonas sp. isolated from paddy soil in Malaysia as biocontrol agent. J. Plant Pathol. Microbiol. $\quad 3$ : $\quad 10.4172 / 2157-$ 7471.1000120

Otadoh, J. A., Sheila, A., Okoth, Ochanda, J., James, P., and Kahindi. 2011. Assessment of Trichoderma isolates for virulence efficacy on Fusarium oxysporum f. sp. phaseoli. Trop. Subtrop. Agroecosys. 13: 99-107.

Pozo. M. J., and Azcón-Aguilar, C. 2007. Unraveling mycorrhiza-induced resistance. Curr Opin Plant Biol. 10: 393-398.

Promwee, A. 2011. Role of Trichoderma spp. as phosphate solubilizing microorganism. Thai Journal of Soils and Fertilizers. 33(1): 17-30.

Promwee, A., Issarakraisila, M., Intana, W., Chamswarng, C., and Yenjit, P. 2014. Phosphate Solubilization and Growth Promotion of Rubber Tree (Hevea brasiliensis Muell. Arg.) by Trichoderma Strains.

Rajappan, K., Vidhyasekaran, P., Sethuraman, K., and Baskaran, T. L. 2002.
Development of powder and capsule formulations of Pseudomonas fluorescens strain Pf-1 for the control of banana wilt. Zeitschrift für Pflanzenkrankheiten und Pflanzenschutz. 109: 80-87.

Raupach, G. S., and Kloepper, J. W. 1998. Mixtures of plant growth-promoting rhizobacteria enhance biological control of multiple cucumber pathogens. Phytopathol. 88: 1158-1164.

Rawat, R., and Tewari, L. 2011. Effect of abiotic stress on phosphate solubilization by biocontrol fungus Trichoderma sp. Current Microbiology. 62(5): 1521-1526. http://dx.doi.org/10. 1007/s00284-011-9888-2.

Schwyn, B., and Neilands, J. B. 1987. Universal chemical assay for the detection and determination of siderophores. Analytical biochemistry. 160: 47-56.

Siddiqui, I. A., Shaukat, S. S., Sheikh, I. H., and Khan, A. 2006. Role of cyanide production by Pseudomonas fluorescens CHAO in the suppression of root-knot nematode, Meloidogyne javanica in tomato. World J Microbiol Biotechnol, 22: 641-650.

Sivamani, E., and Gnanamanickam, S. S. 1988. Biological control of Fusarium oxysporum f.sp. cubense in banana by inoculation with Pseudomonas fluorescens. Plant Soil. 107: 39.

Sivan, A., and Chet, I. 1986. Biological control of Fusarium spp. in cotton, wheat and muskmelon by Trichoderma harzianum. J. Phytopathol. 116: 39-47.

Thangavelu, R., and Gopi, M. 2015. Combined application of native Trichoderma isolates possessing multiple functions for the control of Fusarium wilt disease in banana cv. Grand Naine, Biocontrol Science andTechnology. 25(10): 1147-1164.

Thangavelu, R., and Gopi, M. 2015a. Field 
suppression of Fusarium wilt disease in banana by the combined application of native endophytic and rhizospheric bacterial isolates possessing multiple functions. Phytopathol. Medit. 54: 241252.

Thangavelu, R., Palaniswami, A., and Velazhahan, R. 2004. Mass production of Trichoderma harzianum for managing Fusarium wilt of banana. Agriculture, Ecosytems and Environment. 103: 259-263.

Thangavelu, R., Palaniswami, A., Ramakrishnan, G., Sabitha, D., Muthukrishnan, S., and Velazhahan, R. 2001. Involvement of Fusaric acid detoxification by Pseudomonas fluorescens strain Pf10 in the biological control of Fusarium wilt of banana caused by Fusarium oxysporum f.sp. cubense. Journal of Plant Disease and Protection. 108: 433-445.

Vinale, F., Nigro, M., Sivasithamparam, K., Flematti, G., Ghisalberti, E. L., Ruocco, M., Varlese, R., Marra, R., Lanzuise, S.,
Eid, A., Woo, S. L,. and Lorito, M. 2013. Harzianic acid: a novel siderophore from Trichoderma harzianum. FEMS Microbiol Lett. 347: 123-129.

Weller, D. M., Raaijmakers, J. M., McSpadden Gardener, B. B., and Thomashow, L. S. 2002. Microbial populations responsible for specific soil suppressiveness to plant pathogens. Annual Review of Phytopathology. 40: 309-48.

Xue, C., Penton, C. R., Shen, Z., Zhang, R., Huang, Q., Li, R., Ruan, Y., Shen, Q.R. 2015. Manipulating the banana rhizosphere microbiome for biological control of Panama disease. Sci Reports. 5: 11124.

Zegeye, E. D., Santhanam, A., Gorfu, D., Tessera, M., and Kassa, B. 2011. Biocontrol activity of Trichoderma viride and Pseudomonas fluorescens against Phytophthora infestans under greenhouse conditions. J. Agril. Technol. 7: 1589-1602.

\section{How to cite this article:}

Lalngaihawmi and Ashok Bhattacharyya. 2019. Study on the Different Modes of Action of Potential Trichoderma spp. from Banana Rhizosphere against Fusarium oxysporum f.sp. cubense. Int.J.Curr.Microbiol.App.Sci. 8(01): 1028-1040.

doi: https://doi.org/10.20546/ijcmas.2019.801.112 